\title{
Analytical Methodology for Determination of the Plasma Antioxidant Capacity Through the Radical 2,2-azino-bis-3- ethylbenzthiazoline-6-sulfonic Acid (ABTS)
}

\author{
Aretuza Andrade Ferrante ${ }^{1}$, Isabella Resende Martins ${ }^{1}$, Luecya Alves de Carvalho Silva ${ }^{1}$, Sandro Percário ${ }^{2}$, \\ Michelli Erica Souza Ferreira $^{{ }^{*}}$
}

${ }^{1}$ Federal University of Maranhão, Laboratory of Pathophysiology and Therapeutic Research, Imperatriz, Brazil.

${ }^{2}$ Federal University of Pará, Oxidative Stress Research Laboratory, Belém, Brazil

Correspondence Author: Michelli Erica Souza Ferreira, Federal University of Maranhão, Laboratory of Pathophysiology and Therapeutic Research, Imperatriz, Brazil. E-mail: michelli.ferreira@ufma.br

Received date: 28 January 2019, Accepted date: 13 March 2018, Online date: 28 March 2019

Copyright: () 2019 Aretuza Andrade Ferrante et al, This is an open-access article distributed under the terms of the Creative Commons Attribution License, which permits unrestricted use, distribution, and reproduction in any medium, provided the original author and source are credited.

\begin{abstract}
The method using 2,2-azino-bis (3-ethylbenzthiazoline-6-sulfonic acid (ABTS) is currently used to access the total antioxidant capacity (TAA) of biological samples and is based on the production of its radicals through the reaction with an oxidant. Plasma is a biological matrix used in this method because it has several antioxidant molecules, including metal binding proteins, urate, bilirubin and superoxide dismutase. Nevertheless, it is important to know the limits of its application in the work environment. This knowledge is obtained through validation procedures aiming at characterizing methodological parameters, such as linearity, repeatability, limit of detection and quantification, precision, accuracy and robustness. The objective of this study is to evaluate the ability of ABTS method to access TAA, as well as to determine its reliably and methodological parameters. Plasma from 10 healthy volunteers aged 18-22 years were included in the study. The antioxidant activity was determined by ABTS method. The validation was performed following the recommended procedures. Determination coefficient was 0.9956 . The limits of detection and quantification identified were, in sequence, $0.20 \mathrm{mM}$ and $0.60 \mathrm{mM}$. The test showed accuracy of $107 \%(1.0 \mathrm{mM}), 105 \%(1.5 \mathrm{mM})$ and $101 \%(2.0 \mathrm{mM})$. In the repeatability analysis, the coefficient of variation (CV), in the above concentrations, was $13.48 ; 7.61$ and $5.29 \%$; for intermediate precision were $13.58 ; 9.84$ and $6.68 \%$; and for robustness, were 10,$24 ; 4.47$ and $2.19 \%$. The mean value of plasma antioxidant capacity was 2,05 mM. This study demonstrated that ABTS method had high reliability of application for quantification of total antioxidant activity in human plasma under protocol conditions. However, its methodological parameters should be tested for other biological matrix or, should procedure steps are changed.
\end{abstract}

Key words: Antioxidant status, ABTS, Antioxidant activity, Plasma Antioxidant

\section{INTRODUCTION}

The determination of the antioxidant capacity can be carried out through several parameters, including the metal ion reduction capacity, as ferric reducing antioxidant power (FRAP) and cupric ion reducing antioxidant capacity (CUPRAC); the ablation of a peroxyl radical, such as oxygen radical absorbance capacity (ORAC) and total reactive antioxidant potential (TRAP); radical reduction including ABTS - 2,2'-azino-bis(3-ethylbenzthiazoline-6-sulfonic acid) and DPPH - 2,2-Diphenyl-1-picryl-hydrazyl method, and the verification of the amount of products developed during the lipid peroxidation process (TBARS- thiobarbituric acid reactive substances, oxidation of LDL, or co-oxidation of $\beta$-carotene). The methodologies FRAP, ABTS, DPPH and ORAC are currently the most used for the determination of total antioxidant activity (TAA) in vitro (Duarte-Almeida et al., 2006; Pandey and Rizvi, 2009).

ABTS method is based on the production of the radical $\left(\mathrm{ABTS}^{+\bullet}\right)$ through the reaction with an oxidant system, such as hydrogen peroxide and peroxidase, the radical in contact with the sample containing antioxidants is reduced, promoting reduction of the intensity of initial green color, resulting in decreased absorbance (Kambayashi et al., 2009; Fischer et al., 2005). The advantages of this method include the possibility of being used for both water soluble and liposoluble samples (Miller et al., 1993; Mironczuk-Chodakowska et al., 2018). 
Citation: Aretuza Andrade Ferrante, et al., Analytical Methodology for Determination of the Plasma Antioxidant Capacity Through the Radical 2,2-azino-bis-3ethylbenzthiazoline-6-sulfonic Acid (ABTS). Australian Journal of Basic and Applied Sciences, 13(3): 19-22. DOI: 10.22587/ajbas.2019.13.3.3

Plasma is a biological matrix used for TAA determination through the ABTS $\bullet+$ because it has several antioxidant molecules such as proteins with thiol groups, urates, bilirubin, albumin, ceruloplasmin, transferrin, ferritin and superoxide dismutase (Miller et al., 1993; Mironczuk-Chodakowska et al., 2018).

Differences in the normal TAA values can be caused by changes applied in the methods. Thus, it is important to apply the method appropriately and know its limits of application in a specific work environment. This knowledge is obtained through validation procedures, an essential requirement in the use and adaptation of the methodology, development of new techniques and use of different equipment. The analytical parameters normally used for method validation are linearity, repeatability, limit of detection and quantification, precision, accuracy and robustness (Ministério da Saúde, 2003; Van Amsterdam et al., 2013).

The objective of this research is to demonstrate the limit of detection, limit of quantitation, linearity, accuracy, precision and robustness of ABTS method to access total antioxidant capacity on human blood plasma.

\section{MATERIALS AND METHODS}

The search was conducted in accordance with the Code of Ethics of the World Medical Association (Declaration of Helsinki). Plasma samples were obtained from 10 healthy volunteers (18-22 years), from the University of Medicine of Maranhão, through the centrifugation of $5 \mathrm{~mL}$ of EDTA-blood subjected to centrifugation for 20 minutes (1500 rpm) at room temperature. Presence of disease, smoking, consumption of alcohol was considered as exclusion criteria.

Phosphate buffer (PBS) pH 7.2 and 6.8, 2,2'-azinobis (3-ethylbenzthiazoline-6-sulfonic acid) diammonium salt; potassium persulphate; 6-hydroxy-2,5,7,8-tetramethylchroman-2-carboxylic acid 2,5 mM (Trolox). The reagents were purchased from Sigma Aldrich (St. Louis, MO).

It was used the ABTS method (Miller at al., 1993), with adaptations. To prepare the ABTS ${ }^{+\bullet}, 19.684$ mL of ABTS solution (7 $\mathrm{mM})$ and $352 \mu \mathrm{L}$ of potassium persulfate $(140 \mathrm{mM})$ were mixed and left at room temperature for 16 hours. The study solution (SS) was obtained by adding PBS to the previously prepared solution until the absorbance at $734 \mathrm{~nm}$ reached $0.7 \pm 0.02$ (ABTS \pm $47 \mu \mathrm{M})$. Initially reading was performed on $1970 \mu \mathrm{l}$ of SS (T0), then $30 \mu \mathrm{l}$ of plasma was added, completing a final solution of $2 \mathrm{ml}$, which was shaken and after five minutes a new reading was performed (T5). PBS was used as blank and trolox (1 mM) as standard. The result was obtained by the consumption of radical from the subtraction of the absorbance of T5 of the one ident ified in $\mathrm{T} 0$ and dividing them by T0, thus obtaining a TAA (T0-T5/T0=TAA), and it was expressed as trolox equivalent (mM). The blank TAA is subtracted the sample TAA to obtain the corrected TAA (TAAc).

Validation was performed in triplicate, following the procedures recommended (Ministério da Saúde, 2003; Van Amsterdam et al., 2013).

Repeatability and intermediate accuracy were evaluated using three concentrations of trolox (1.0, 1.5 and 2.0 mM). Solutions for repeatability were prepared in PBS $(\mathrm{pH}=7.2)$ on the day of determination, and for two consecutive days by separate examiners for between - run precision assessment.

In linearity the same previous concentrations and two other solutions with Trolox $(0.5$ and $2.5 \mathrm{mM})$.

The concentrations quoted in repeatability were prepared with phosphate buffer $\mathrm{pH} 6.8$ for analysis of the robustness.

In exactness the three concentrations measures were used and the measured one (Cmeas) was compared to the actual value (Cactual).

Limit of detection (LD) and of quantitation (LQ) were obtained by statistical analysis.

We used the Action Stat 3.4.152.34 for descriptive statistics, to determine limit of detection and limit of quantitation. The linearity was analysed by Pearson's correlation coefficient using BioEstat 5.3.

\section{RESULTS AND DISCUSSION}

The linear concentration range obtained by the proposed method demonstrates a correlation coefficient (R2) higher than 0.99 (Figure 1), which shows perfect compliance with the current recommendations (Ministério da Saúde, 2003; Van Amsterdam et al., 2013).

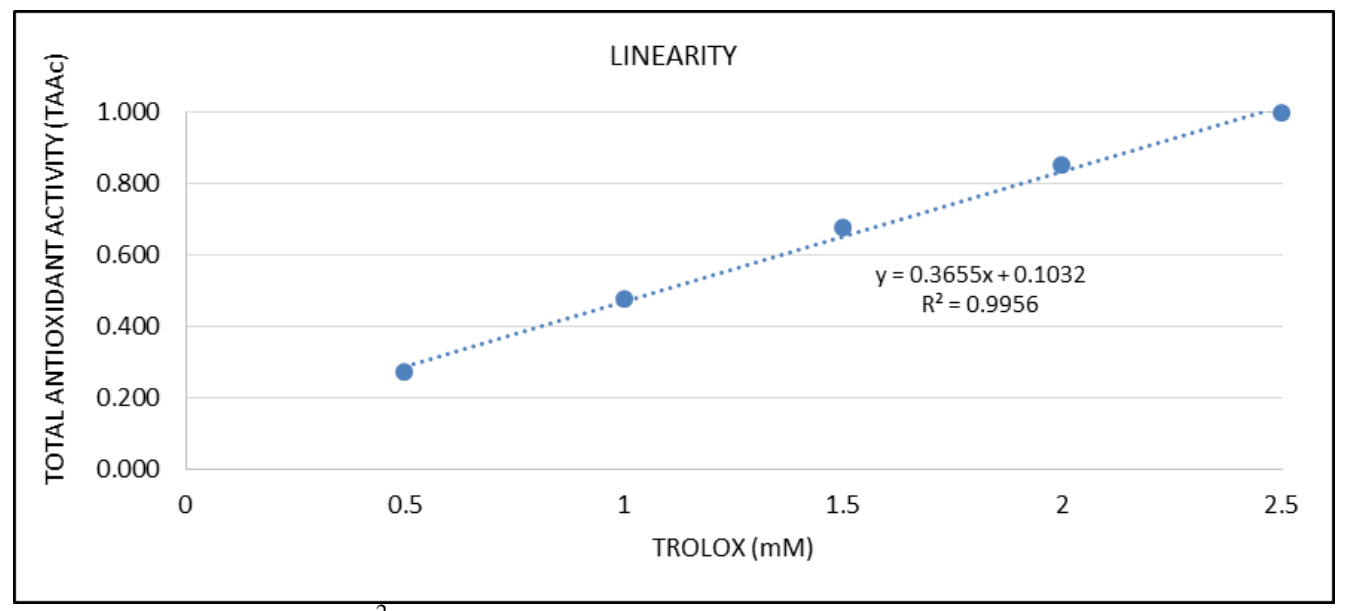

Figure 1: Linearity of the ABTS method. $\mathrm{R}^{2}=$ Pearson's correlation coefficient. 
Through the analysis of repeatability, precision and robustness it was observed in Table 1 that the method did not present daily changes or changes imposed by different analysts and $\mathrm{pH}$, as the determined CV are less than 15\% (Ministério da Saúde, 2003; Van Amsterdam et al., 2013).

Table 1: Results of repeatability, accuracy and robustness

\begin{tabular}{|c|c|c|c|c|c|c|}
\hline & \multicolumn{2}{|c|}{ Trolox (mM) } & \multicolumn{2}{|c|}{ Absorbanc } & \multicolumn{2}{|c|}{ CV \% } \\
\hline & \multicolumn{2}{|c|}{1.0} & 0.587 & 0.472 & 0.465 & 13.48 \\
\hline Repeatability & \multicolumn{2}{|c|}{1.5} & 0.764 & 0.672 & 0.670 & 7.61 \\
\hline & \multicolumn{2}{|c|}{2.0} & 0.927 & 0.850 & 0.844 & 5.29 \\
\hline \multirow{6}{*}{$\begin{array}{l}\text { Between - run precision } \\
\text { (Different analysts) }\end{array}$} & \multirow{2}{*}{1.0} & A & 0.590 & 0.596 & 0.468 & 13.58 \\
\hline & & $\mathrm{B}$ & 0.598 & 0.461 & 0.462 & \\
\hline & \multirow{2}{*}{1.5} & $\mathrm{~A}$ & 0.786 & 0.788 & 0.797 & 9.84 \\
\hline & & $\mathrm{B}$ & 0.664 & 0.671 & 0.648 & \\
\hline & \multirow{2}{*}{2.0} & $\mathrm{~A}$ & 0.927 & 0.923 & 0.922 & 6.68 \\
\hline & & $\mathrm{B}$ & 0.822 & 0.818 & 0.814 & \\
\hline \multirow{6}{*}{$\begin{array}{c}\text { Robustness } \\
\text { (pH } 6.8 \text { and 7.2) }\end{array}$} & \multirow{2}{*}{1.0} & 6.8 & 0.471 & 0.475 & 0.589 & 10.24 \\
\hline & & 7.2 & 0.569 & 0.587 & 0.575 & \\
\hline & \multirow{2}{*}{1.5} & 6.8 & 0.672 & 0.670 & 0.664 & 4.47 \\
\hline & & 7.2 & 0.732 & 0.712 & 0.728 & \\
\hline & \multirow{2}{*}{2.0} & 6.8 & 0.850 & 0.848 & 0.853 & 2.19 \\
\hline & & 7.2 & 0.892 & 0.882 & 0.877 & \\
\hline
\end{tabular}

Analyst A; Analyst B; Coefficient of Variation (CV) calculated according to Ministério da Saúde, (2003).

From the values of LQ $(0.20 \mathrm{mM})$ and $\mathrm{LD}(0.60 \mathrm{mM})$, it is verified that the method has high sensitivity to detect and quantify small amounts of TAAc in plasma (Ribani et al., 2004). The mean value of plasma TAAc was $2.05 \pm 0.02 \mathrm{mM}$.

The test showed accuracy of $107 \%(1.0 \mathrm{mM}), 105 \%(1.5 \mathrm{mM})$ and $101 \%(2.0 \mathrm{mM})$. According to recommendations, the exactness should be close to $100 \%$ (Van Amsterdam et al., 2013). Values ranging from 85 to $115 \%$ are recommended, since a complex matrix, small concentration, and multiple step method was used (Ribani et al., 2004).

The TAA assay in plasma of the present study $(2.05 \mathrm{mM})$ showed values within the normal range, 1.85 to $2.31 \mathrm{mM}$ (Ondei et al., 2009). Similar data were found in another study of the antioxidant status of healthy individuals (aged 16-25 years). It was performed by means of TAA measurement, using the same analysed matrix, and obtained values of $2.17 \pm 0.10 \mathrm{mM}$ (Ondei et al., 2014). Moreover, authors proposed that TAA decreases significantly in older individuals.However, also studying clinically healthy individuals aged 18-25 years, found higher values of $3.1 \pm 0,6 \mathrm{mM}$, but TAA was quantified by colorimetric ABTS method, using a commercial determination kit (Costa et al., 2017). Also, in healthy subjects aged 27-36 years, was found 0.96 \pm $0.10 \mathrm{mM}$ of TAA in serum determination using the ABTS kit (Önninga et al., 1998). Level of TAA on control subjects was $0.47 \pm$ $0.14 \mathrm{mM}$ of plasma TAA, determined using an antioxidant assay kit (Vichaibun et al, 2019) from a different manufacturer than of Costa et al. (2017). In those studies the results are expressed as molar equivalents (mM) of Trolox.

From the above, it is observed that the method of determination of TAA using ABTS (Miller at al., 1993) specifications, presented corroborative results, whereas the use of different procedures, such as commercial kit (Costa et al., 2017), or different matrix (Önninga et al., 1998), TAA values may vary, as expected.

\section{CONCLUSION}

The study demonstrates that the indicated method offers high reliability for quantification of TAA in plasma. Providing reliable, robust, and accurate data proportional to the TAA sample concentration. Therefore, it can be used to analyse the oxidative stress of human plasma sample under study in comparison to the control or to verify changes in the antioxidant capacity after the ingestion of a certain food rich in antioxidants.

\section{ACKNOWLEDGEMENT}

We thank the volunteers who participated in this study.

\section{RESEARCH FUNDING}

This study was supported by the Foundation for Support to Research and Scientific and Technological Development of Maranhão (FAPEMA, Brazil).

\section{DECLARATION OF INTEREST}

The authors declared no conflicts of interest with respect to the authorship and/or publication of this article. 
Citation: Aretuza Andrade Ferrante, et al., Analytical Methodology for Determination of the Plasma Antioxidant Capacity Through the Radical 2,2-azino-bis-3ethylbenzthiazoline-6-sulfonic Acid (ABTS). Australian Journal of Basic and Applied Sciences, 13(3): 19-22. DOI: 10.22587/ajbas.2019.13.3.3

\section{REFERENCES}

Costa, J.O., Vásquez, C.M.P., Santana, G.J., Silva, N.J., Braz, J.M., Jesus, A.M.R., Silva, D.G.D., Cunha, L.C.S., Barbosa, K.B.F. 2017. Capacidade Antioxidante Total do Plasma e Risco Cardiometabólico em Adultos Jovens, Não Obesos e Clinicamente Saudáveis Plasma Total Antioxidant Capacity and Cardiometabolic Risk in Non-Obese and Clinically Healthy Young Adults. Arq Bras Cardiol, 109:140-147. DOI: 10.5007/2175-7925.2014v27n3p167.

Duarte-Almeida, J.M., Santos, R.J., Genovese, M.I., Lajol,o F.M. 2006. Avaliação da atividade antioxidante utilizando sistema $\beta$ caroteno/ácido linoléico e método de sequestro de radicais DPPH. Cienc Tecnol Aliment, 26:446-52. DOI: 10.1590/S010120612006000200031.

Fischer, M.A.J.G., Gransier, T.J.M., Beckers, L.M.G., Bekers, O., Bast, A., Haenen, G.R. 2005. Determination of the antioxidant capacity in blood. Clin Chem Lab Med, 43 (7):735-140. DOI: 10.1515/CCLM.2005.125.

Kambayashi, Y., Binh, N.T., Asakura, H.W., Hibino, Y., Hitomi, Y., Nakamura, H., Ogino, K. 2009. Efficient assay for total antioxidant capacity in human plasma using a 96-well microplate. J Clin Biochem Nutr, 44 (1):46-51. DOI: 10.3164/jcbn.08162.

Miller, N.J., Rice-Evans, C., Davies, M.J., Gopinathan, V., Milner, A. 1993. A novel method for measuring antioxidant capacity and its application to monitoring the antioxidant status in premature neonates. Clin Sci, 84 (4):407-412. DOI: $10.1042 / \mathrm{cs} 0840407$.

Ministério da Saúde, 2003. Agência Nacional de Vigilância Sanitária. Guia para Validação de Métodos Analíticos. Resolução nº 899, de 29 de maio de 2003. Available at http://portal.anvisa.gov.br/documents/10181/2718376/RE_ 899_2003_COMP.pdf/ff6fdc6b-3ad1-4d0f-9af2-3625422e6f4b.

Mironczuk-Chodakowska, I., Witkowska, A.M., Zujko, M.E. 2018. Endogenous non-enzymatic antioxidants in the human body. Adv Med Sci, 63 (1):68-78. DOI: 10.1016/j.advms.2017.05.005.

Ondei, L.S., Silveira, L.O., Leite, A.A., Souza, D.R., Pinhel, M.A., Percário, S., Ricci Júnior, O., Bonini-Domingos, C.R. 2009. Lipid peroxidation and antioxidant capacity of G6PD-deficient patients Zith A-(202G>A) mutation. Genet Mol Res, 8(4):1345-1352. DOI: 10.4238/vol8-4gmr662.

Ondei, L.S., Teresa, F.B., Bonini-Domingos, C.R. 2014. Avaliação de fatores preditivos de estresse oxidativo em pessoas saudáveis. Rev Biotema, 27(3):167-173. DOI: 10.5007/2175-7925.2014v27n3p167.

Önninga, G., Åkessona, B., Östea, R., Lundquist I. 1998. Effects of Consumption of Oat Milk, Soya Milk, or Cow’s Milk on Plasma Lipids and Antioxidative Capacity in Healthy Subjects. Ann Nutr Metab, 42 (4):211-220. DOI: 10.1159/000012736.

Pandey, K.B., and Rizvi, S.I. 2010. Markers of oxidative stress in erythrocytes and plasma during aging in humans. Oxid Med Cell Longevity, 3:2-12. DOI: 10.4161/oxim.3.1.10476.

Ribani, M., Bottoli, C.B.G., Meto, L.F.C. 2004. Validação de métodos cromatográficos e eletroforéticos. Rev Quim Nova, 27 (5):771-780. DOI: 10.1590/S0100-40422004000500017.

Van Amsterdam, P., Companjen, A., Brudny-Kloeppel, M., Golob, M., Luedtke, S., Timmerman, P. 2013. The European Bioanalysis Forum community's evaluation, interpretation and implementation of the European Medicines Agency guideline on Bioanalytical Method Validation. Bioanalysis, 5 (6):645-59. DOI: 10.4155/bio.13.19.

Vichaibun, V., Khananurak, K., Sophonnithiprasert, T. 2019. Comparative analysis of plasma total antioxidant capacity in patients with hyperglycemia and hyperglycemia plus dyslipidemia. Diabetes Metab Syndr, 13 (1):90-94. DOI: 10.1016/j.dsx.2018.08.029. 